\title{
Field testing of morphing flaps on a wind turbine blade using an outdoor rotating rig
}

\author{
Ai, Qing; Weaver, Paul M.; Barlas, Athanasios; Olsen, Anders Smærup; Aagaard Madsen , Helge; \\ Løgstrup Andersen, Tom
}

\section{Published in:}

Renewable Energy

Link to article, DOI:

10.1016/j.renene.2018.09.092

Publication date:

2019

Document Version

Peer reviewed version

Link back to DTU Orbit

Citation (APA):

Ai, Q., Weaver, P. M., Barlas, A., Olsen, A. S., Aagaard Madsen , H., \& Løgstrup Andersen, T. (2019). Field testing of morphing flaps on a wind turbine blade using an outdoor rotating rig. Renewable Energy, 133, 53-65. https://doi.org/10.1016/j.renene.2018.09.092

\section{General rights}

Copyright and moral rights for the publications made accessible in the public portal are retained by the authors and/or other copyright owners and it is a condition of accessing publications that users recognise and abide by the legal requirements associated with these rights.

- Users may download and print one copy of any publication from the public portal for the purpose of private study or research.

- You may not further distribute the material or use it for any profit-making activity or commercial gain

- You may freely distribute the URL identifying the publication in the public portal 


\section{Accepted Manuscript}

Field testing of morphing flaps on a wind turbine blade using an outdoor rotating rig

Qing Ai, Paul M. Weaver, Thanasis K. Barlas, Anders S. Olsen, Helge A. Madsen, Tom L. Andersen

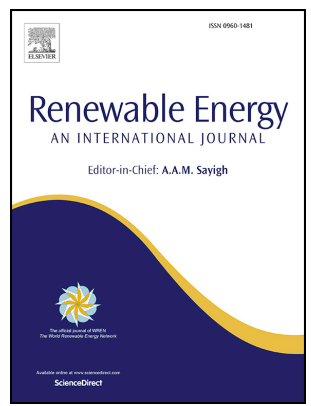

PII: S0960-1481(18)31166-2 $\quad$ S

DOI: $\quad$ 10.1016/j.renene.2018.09.092

Reference: RENE 10632

To appear in: Renewable Energy

Received Date: 7 April 2018

Revised Date: 22 September 2018

Accepted Date: 25 September 2018

Please cite this article as: Ai Q, Weaver PM, Barlas TK, Olsen AS, Madsen HA, Andersen TL, Field testing of morphing flaps on a wind turbine blade using an outdoor rotating rig, Renewable Energy (2018), doi: https://doi.org/10.1016/j.renene.2018.09.092.

This is a PDF file of an unedited manuscript that has been accepted for publication. As a service to our customers we are providing this early version of the manuscript. The manuscript will undergo copyediting, typesetting, and review of the resulting proof before it is published in its final form. Please note that during the production process errors may be discovered which could affect the content, and all legal disclaimers that apply to the journal pertain. 
In recent years, active flap devices on wind turbine blades have been shown to both reduce peak loads at the tower and extend blade fatigue life. Associated benefits include retrofitting existing tower infrastructure with longer and greater energy-producing blades whilst also extending service life of blades. In the current work, a novel wind turbine blade control method using morphing flaps has been successfully investigated and demonstrated using a scaled demonstrator mounted on an outdoor rotating test rig. Shape adaptive structures that remain conformal to the flow are increasingly referred to as morphing devices. As part of the INNWind.eu project, a novel morphing flap device was developed for a recently designed aerofoil. The proposed morphing flap comprises a light-weight carbon fibre laminate, 3D printed honeycomb core and a flexible silicone surface. A comprehensive test campaign using an outdoor rotating test rig under atmospheric conditions was carried out to assess the potential effectiveness. As shown by experimental data, the morphing flap provides good performance in terms of aerodynamic lift control of the 
blade and can provide dynamic load alleviation capability.

Keywords: morphing flap, turbine blade, load control, rotating test rig, dynamic

\section{Introduction}

Modern wind turbine blades are of increasingly larger size due to ever growing demand for reduced cost of energy, which brings in new challenging requirements of light-weight structures and efficient load control methods including dynamic fatigue loads. Conventional mechanical systems using pitch and yaw control become cumbersome for turbine blades of significantly increased size in terms of reaction speed and actuation energy requirements $[1,2,3,4,5,6,7,8,9,10]$ As such, light-weight shape adaptive structures, conformal to flow and known as morphing technologies are currently being considered as the next generation of integrated blade design solutions for enhanced efficiency and improved performance $[11,12,13,14,15,16,17,18$, $19]$.

Unlike pitch and yaw mechanical systems which move the entire blade in response to dynamic operation conditions, morphing structures can provide local blade profile changes to control aerodynamic pressure distribution, both span-wise and chord-wise, which possibly alleviate gust loads. Featuring integral structural designs, morphing structures are characterised by continuous outer surfaces and smooth geometric variations, and by doing so facilitate the conformality of blade structures. The seamless structural design is also beneficial from an aeroacoustic perspective compared to conventional hinged flaps that are widely used on current aircraft [17]. 
Various morphing concepts and designs have been proposed in recent years and a few have been sucessfully demonstrated for applications on aeroplane wings and wind turbine blades $[6,7,15,17,18,19]$. Daynes et al. designed a wind turbine morphing trailing edge consisting of a carbon fibre reinforced plastic (CFRP) laminate on the pressure side, a silicone sheet on the suction side and a hexagonal honeycomb core providing the throughthickness reinforcement. A CFRP rod, constrained to the bottom surface of the core and tied to the trailing edge, was used to push/pull the flap tip as an actuation method. The morphing flap proposed was successfully tested for large trailing edge deformations powered by an on-shelf electric servomotor. Wind tunnel experiments confirmed the aerodynamic performance improvement of the morphing flap device. Following Daynes et al, Ai and Weaver [17] extended the morphing flap concept by introducing a 3D printed honeycomb core featuring zero Poisson's ratio and spatially tailored stiffness in the design. The carefully selected honeycomb core enabled the morphing flap to provide targeted morphing profiles, which significantly enlarged the performance and structural design envelope. In a later study by the authors [20], a design optimization methodology was further developed for the morphing flap using stiffness tailored honeycomb core and the morphing flap was benchmarked with experimental tests on a demonstrator.

Though promising progress has been made with regard to morphing concepts, material selection and realistic actuation solutions, there still remain significant challenges to further increase the associated technology readiness level of morphing technologies for mature commercialization. The incentive of this paper is to demonstrate the usage of a morphing flap on a wind tur- 
bine blade for aerodynamic lift control and dynamic load alleviation purposes when combined with inflow sensors (see Fig.1). The testing activities carried out in the campaign in this paper bridges the divide between lab-scale tested morphing flaps $[13,14,15,16,17]$ and the realistic commercialisation of such control surfaces as wind turbine flow control devices. The test campaign using an outdoor rotating rig in DTU's Risø campus provides an excellent opportunity to mature morphing concepts and to explore potential barriers[8]. This study of design, building and testing of morphing flaps is considered to be a significant advance in morphing structure applications, which, to the authors' knowledge, is among the first of its kind. The morphing trailing edge concept selected in this paper, as shown in Fig.1, has been under continuous research and development in recent years $[15,16,17,20]$. The paper is organized as follows: firstly, the morphing flap concept is introduced, along with specific design requirements and associated numerical models predicting the structural responses; secondly, a demonstrator manufacturing process is described in detail followed by descriptions of the in-house mechanical testing results; thirdly, the outdoor rotating rig testing and results are presented with conclusive summaries and the paper then finishes with remarks on future work.

\section{The morphing flap concept}

The wind turbine blade aerofoil used in our morphing flap design, ECNG30-18-60, was newly designed by the Energy Research Centre at the Netherlands (ECN) through a series of optimization design studies[9]. The asymmetric aerofoil has large thickness at the first $50 \%$ chord length and the 


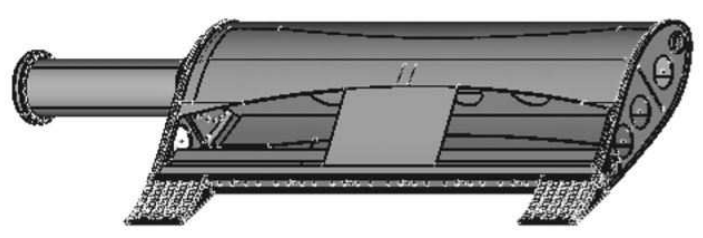

Figure 1: A turbine blade with a morphing trailing edge device (flap skins are removed for purpose of clarity).

trailing edge has a relatively flat upper surface while the lower surface is cambered. Considering the outdoor testing rig specifications, the morphing flap design requirements are given as: the morphing flap should extend to the full span, $2 \mathrm{~m}$, of the turbine blade and account for $20 \%$ of the $1 \mathrm{~m}$ aerofoil chord length, namely $200 \mathrm{~mm}$. Based on the actuation method viability and ease of inter-changeability of the morphing flaps, eight uniform morphing trailing edges that have a span of $249 \mathrm{~mm}$ each are arranged along the turbine blade span and powered by a servomotor inside the blade profile.

After a down-selection of the morphing concepts, the morphing trailing edge designed and benchmarked by Ai and Weaver[17, 20] was chosen for use. As shown in Fig.2, the morphing flap device consists of four components: 1) a CFRP laminate upper skin on the suction side of the aerofoil; 2) a 3D printed honeycomb core of zero Poisson's ratio along the aerofoil chord providing the through-thickness support to the structure; 3) a pre-tensioned silicon lower skin on the pressure side to provide a smooth aerodynamic surface and 4) a CFRP rod to act as an actuation rod. The upper laminate skin is $0.4 \mathrm{~mm}$ thick and has a layup of $[90 / 0 / 90]^{\circ}$ with $0^{\circ}$ aligning with the aerofoil chord. 


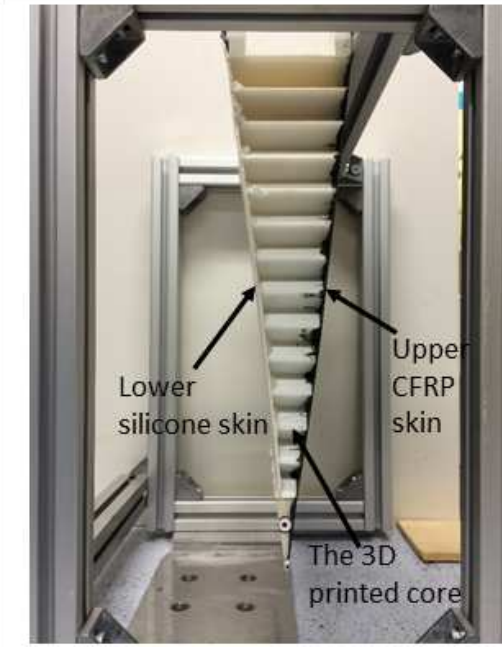

(a) Side view of the demonstrator

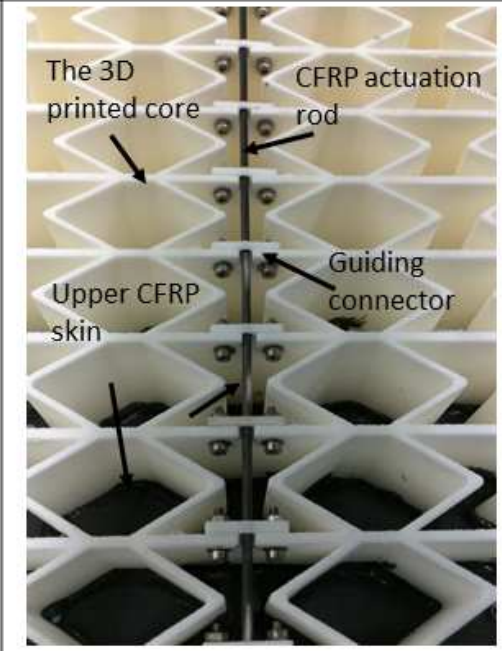

(b) top view of the demonstrator without the silicone skin

Figure 2: The morphing flap design using 3D printed honeycomb core[20].

The composite material used is Hexcel IM7/8550 carbon/epoxy prepeg. Honeycomb cores have been widely used in many morphing structures for their highly anisotropic mechanical properties and light weight [21, 22]. However, in many one-dimensional morphing behaviours, zero Poisson's ratio honeycomb core receives growing interest due to its ability to provide large deformation in one direction without causing geometric changes in the perpendicular direction $[23,24,25]$. In the morphing trailing edge studied in this paper, a zero Poisson's ratio honeycomb core was designed and then manufactured using Laser-Sintering technology by i.Materialise with polyamide powder [20].

One CFRP push/pull rod was selected as the actuation method for the morphing flap designed. The rod is attached to the honeycomb core through 
fixing holes on the honeycomb core's cell walls and glued to the trailing edge using epoxy resin. These connections allow the rod to move in/out along the bottom surface of the honeycomb core without any movement along the through-thickness direction. The rod is sufficiently stiff to carry and transfer the actuation load to the core and also has the flexibility to bend with the core avoiding internal structural distortion. The rod used has a diameter of 2 mm with a longitudinal Young's modulus of $150 \mathrm{GPa}$ and a lateral Young's modulus of $10 \mathrm{GPa}$.

The finite element method (FEM) was used in the preliminary design phase to quantify the structural responses of the morphing flap under actuation forces and aerodynamic pressure loads. The main objective was to obtain the trailing edge displacement-actuation load curve for the actuator selection purposes. The FEM model was prepared using commercial software, ABAQUS. Skins and honeycomb core wer modelled using S4R shell elements and the CFRP actuation rod was modelled using B31 beam elements. Geometry non-linearity was considered in the ABAQUS model considering the designed large morphing flap deformation. The actuation rod is constrained to the bottom surface of the core at the mid-span using coupling constraints which have removed the rod's degree of freedom along the thickness of the core. Clamped boundary conditions are applied at the rear spar of the morphing flap. Displacement boundary conditions are applied at the free end of the actuation road while the other end of the rod is tied to the flap trailing edge. Reaction forces at the free end of the rod are recorded for different given flap trailing edge deflections and logged as the actuation-deflection diagram. In order to account for the testing environment of the rotating rig, 
the centrifugal forces and aerodynamic pressure loads on the flap are considered in the FEM model. The centrifugal forces were applied by providing a spinning angle speed for the whole blade structure around a rotating axis defined in the model according to the outdoor rig design. Pressure loads on the flap for varying angles of attack together with flap deformation were calculated using Xfoil[26]. The peak pressure loads on the flap were chosen as the design parameter and applied on the flap surface in the FEM model for maximum structural safety purposes. However, due to the morphing flap's light weight nature, the centrifugal forces were found to have an insignificant effect on the actuation force requirements. At the same time, it is worth noting that the pressure loads on the morphing flap can significantly change the actuation force (up to 15\%) depending on the flap deflection direction. With FEM analyses of the proposed flap design, it was found that for a flap with selected size and materials, an actuation force range of $-250 \mathrm{~N}$ to $200 \mathrm{~N}$ is required, which is comparable to findings in Refs $[16,17,20]$. The actuation system in question is incorporated into the blade section and is described in a later section.

\subsection{Building and testing of the morphing flap demonstrator}

After the detailed FEM analyses was done to guide the design, a prototype demonstrator was built in the structural lab of ACCIS for two purposes: to perform mechanical experiments validating the FEM and to better understand and explore the manufacturing process. In the proposed manufacturing process, the morphing flaps are built in four parallel steps: 1) the zero Poisson's ratio honeycomb core was designed and ordered from an external 3D printing service supplier; 2) the CFRP rod was then installed to the bottom 
side of the core, penetrating through the guiding holes on the core cell walls and glued to the core tip using epoxy resin; 3) a pre-fabricated CFRP skin was glued to the upper side of the core and 4) a pre-tensioned rubber sheet was then attached to the bottom surface of the core with a thin layer of rubber glue. Note, the rear spar of the honeycomb core was designed to facilitate the easy connection between the flap and the blade section. Specific mouldings were rapid-prototyped using a Makerbot Replicator table 3D printer, which allows for low cost tooling with reasonably good quality. These in-house moulds ensure flap dimension stability, especially for the skin, honeycomb core and the glue layer thickness control.

In the manufacturing phase, two different ways of installing the CFRP actuation rod were proposed and tested. In the first method, the honeycomb core used in the morphing flap was split into two parts: a rigid tip and a flexible core section. The tip and the core section can be joined mechanically for an easy and quick replacement. The actuation rod is connected to the flap tip (3D printed plastic part or CNC machined aluminium part) using mechanical linkages including a threaded rod head and an inserted coil in the tip. In the trial cases carried out at the ACCIS structural laboratory, a rigid tip section was produced using ABS plastic with a Stratasys rapid prototyping machine. A helical coil was then inserted into the tip with a corresponding threaded head installed on the actuation rod end. Such a design allows for rapid interchange and replacement of broken components, which is economically advantageous. However, due to the brittle nature of the ABS plastic used, the helical coil slipped out of the tip section during a fatigue test. It is envisaged that changing the ABS plastics to aluminium would im- 
prove the quality and reliability of the proposed design. The second method was then proposed and tested due to time and budgetary considerations. In the chosen design, an integrated honeycomb core was selected and the CFRP rod was then connected to the tip section using epoxy glue before skins were added. This joining method provided a robust and reliable performance for the demonstrators, but limits the possibility of replacement of broken components. However, at the early stage of the testing plan, it serves as a better option with relatively low cost and ease of manufacturing compared to the first method and continues to be used in the following manufacturing process.

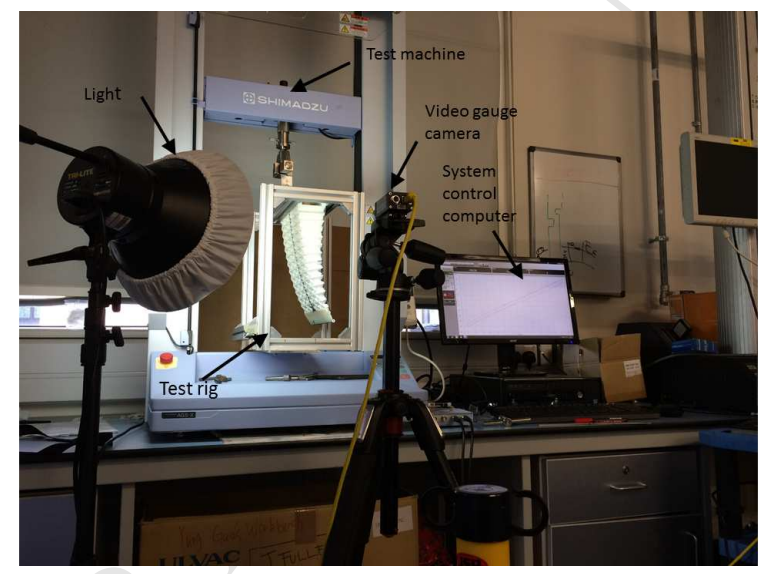

Figure 3: Structural responses characterization of the morphing flap using a video gauge system.

The demonstrator was subsequently tested to characterize actuation requirements and particularly its fatigue performance to ensure the completion of the the entire test campaign. The static mechanical test set-up is shown in Fig.3. A test rig was prepared to support the demonstrator with the morphing trailing edge fixed to the top spars of the rig. The CFRP actuation rod was connected to the $1 \mathrm{kN}$ load cell of a Schimadzu universal tensile 


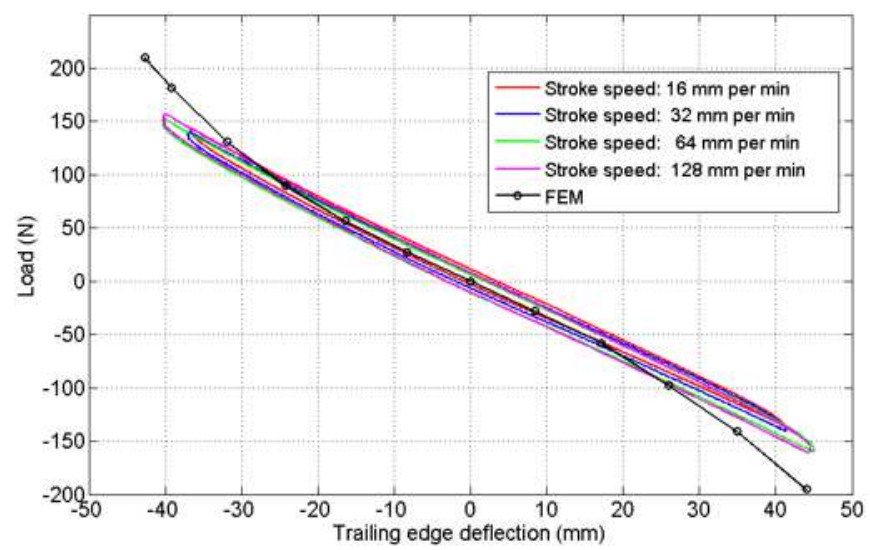

Figure 4: The actuation requirement of the morphing flap demonstrator.

testing machine. In the tests, stroke control is used which applies displacements to the actuation rod and the corresponding reaction load is monitored. An Imetrum video gauge system (see Fig.3) measured the real-time deformed shape of the morphing trailing edge and simultaneously recorded the load/stroke data. Different test speeds were used in the test campaign. Fig.4 presents measured actuation force requirements of the morphing flap demonstrator at various stroke speeds. Results show that the FEM model provides accurate prediction of the actuation force relative to the experimental measurements. Testing speed was not found to significantly affect the actuation forces at this static testing bench. Furthermore, the fatigue performance of the proposed morphing flaps are of utmost importance during the testing campaign and hereby investigated in the laboratory before the outdoor tests were undertaken. Based on the results shown in Fig. 4, the flap demonstrator was set to reach a trailing edge deflection of $45 \mathrm{~mm}$ towards both the pressure and suction sides, which is approximately $4.5 \%$ of 
the aerofoil chord. As the aim of the fatigue test is to ensure that the morphing flaps can survive the holistic testing campaign including the trial cases in DTU laboratory and the outdoor rotating testing, a low cycle number of 10,000 was selected in the tests which provides sufficient margin for the entire testing activities. However, for a certified wind turbine blade structures, a fatigue test in order of 1 to 10 million cycles is demanded which is beyond the scope of our current research. The morphing flap demonstrator successfully passed the fatigue test without any damaged being noticed. However, it is recommended that a comprehensive study of the morphing flap's fatigue performance be undertaken for further development of the morphing flap.

\section{The blade section development}

The outdoor rotating test rig situated at DTU Ris $\varnothing$ Campus plays an important experimental role filling in the gap between full-scale MW experiments and wind tunnel tests for aerodynamic and aero-servo-elastic experiments on turbine blades. In flap testing activities on the rotating test rig in the INDUFLAP project[8], a beam that deforms elastically underpins the test. On the outer part of the beam different elements to be tested can be mounted for characterization of aerofoil characteristics through pressure measurements. Besides the main boom, a counter weight is mounted to balance the beam and the aerofoil section. During the measurements the turbine is driven by a motor which precisely controls rotational speeds. The idea behind the test rig is that the testing should be as close as possible to the operational environment of the real turbine and have the same unsteady inflow conditions and a size of the flap close to a full scale application. These 
conditions were obtained by manufacturing a blade section with a $1 \mathrm{~m}$ chord and $2 \mathrm{~m}$ span and mounting it on a $10 \mathrm{~m}$ long boom on the rotating rig. A detailed instrumentation of the test rig has been carried out. Sensors are installed for the blade surface pressure measurements on the mid span position, which enables a continuous monitoring of the instantaneous sectional aerodynamic loading on blade, and thus also allows for measuring the exact response of flap actuation. Another part of the instrumentation comprises two five-hole pitot tubes placed at the leading edge of the blade section for measuring the inflow to the blade. Finally, metrological data such as wind speed and direction are measured at three heights in a nearby met mast.

The testing bed of the morphing flap design consists of a spanwise 2.0 m long section, with a constant cross section of the ECN-G30-18-60, having a chord of $1.0 \mathrm{~m}$ covered with composite side pods in each end giving a total length of $3.25 \mathrm{~m}$. The section has an inner aluminium skeleton covered with shells of composite material and hatches for easy access to the instrumentation inside blade. The section was dimensioned for test up to $30 \mathrm{rpm}$. The actuation system of the morphing flap and the adapter for mounting of the flap was designed in accordance with the morphing flap characteristics. The blade section was instrumented with 57 pressure taps distributed in the chord-wise direction at the mid-span position of the wing. Two of the taps were installed inside the trailing edge of the flap. Furthermore, 16 pressure taps were distributed along the span of the wing at $27 \%$ of the chord length from the leading edge. The pressure scanner used in the testing campaign is the Scanivalve DSA 3217 Pressure scanner model. Considering the actuation requirements, the eight uniform morphing trailing edges are actuated in 


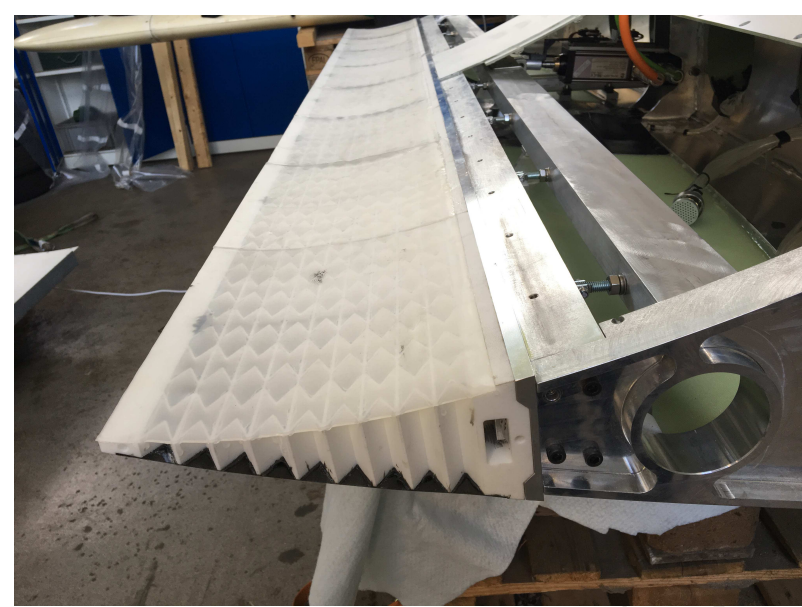

(a) The integrated actuation mechanism in the blade section.

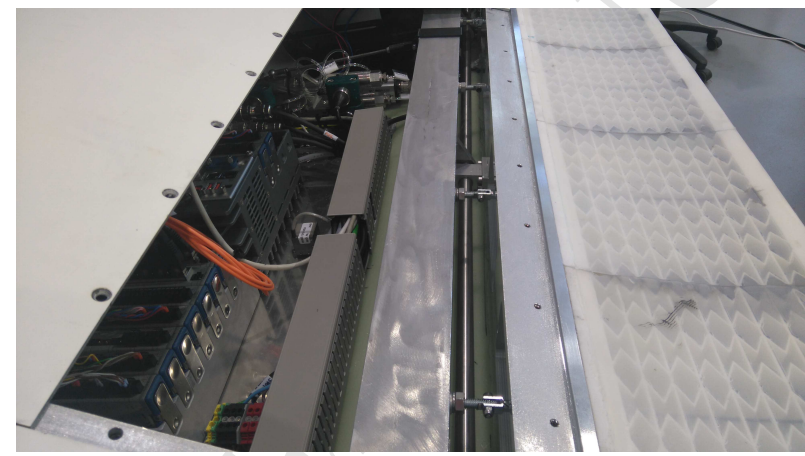

(b) Flaps and blade section mounting design.

Figure 5: The integrated actuation mechanism in the blade section.

a connected motion using a linear motion servo-motor, a EXLAR K Series linear electric linear actuator with a maximum force of up to $15 \mathrm{kN}$, as shown in Fig.5.

\subsection{The rotating rig and test cases}

In this measurement campaign, signals from various sensors on the rotating rig and the mast were recorded. Data channels involve sensor signals related to: operation of rotating rig (rotor speed, rotor azimuth, yaw an- 


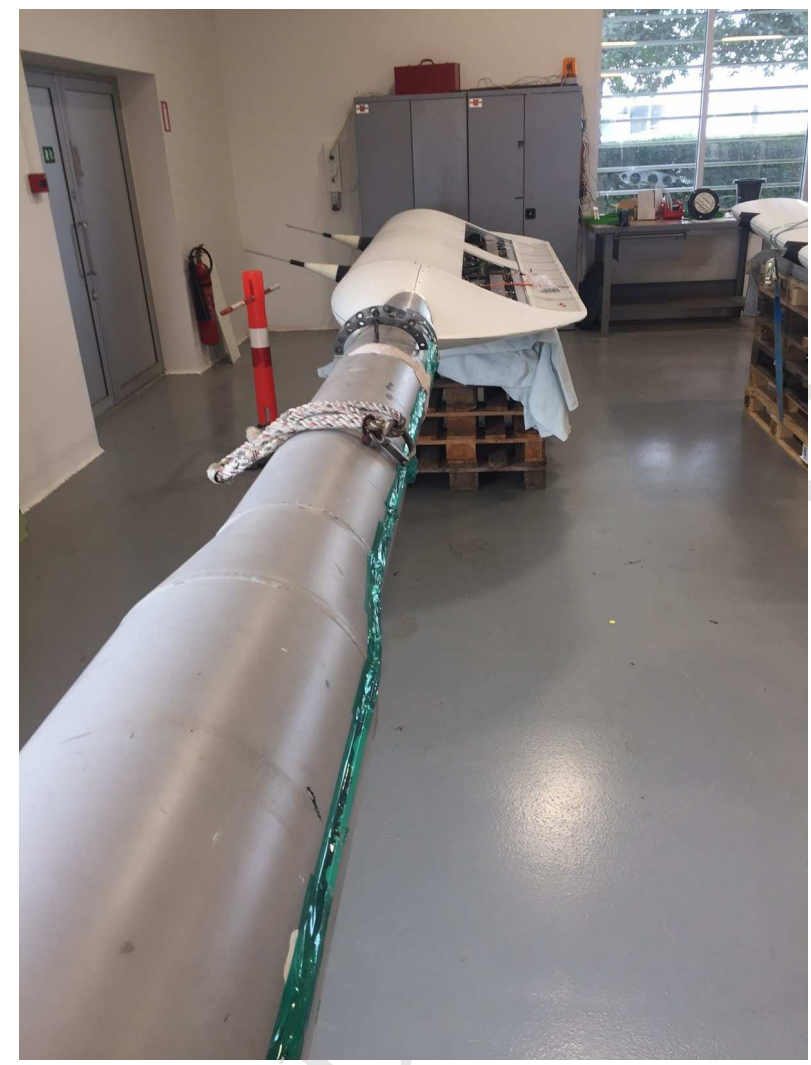

Figure 6: The turbine blade section fitted with morphing flaps and mounted on the boom before installation.

gle), inflow (wind speed and direction), flap operation (flap angle), blade section aerodynamics (pressure distribution from 57 chordwise and 16 spanwise pressure taps, 2 Pitot tubes inflow angle and velocity) and boom and blade section structural response (flapwise and edgewise strains at the root and at the wing, flapwise and edgewise acceleration at the wing). In total, 130 data channels were recorded. The sensor signals in use have been converted from a raw (voltage) signal into a physical quantity already through the acquisition software processing.

It is important to observe the performance of the blade section and mor- 


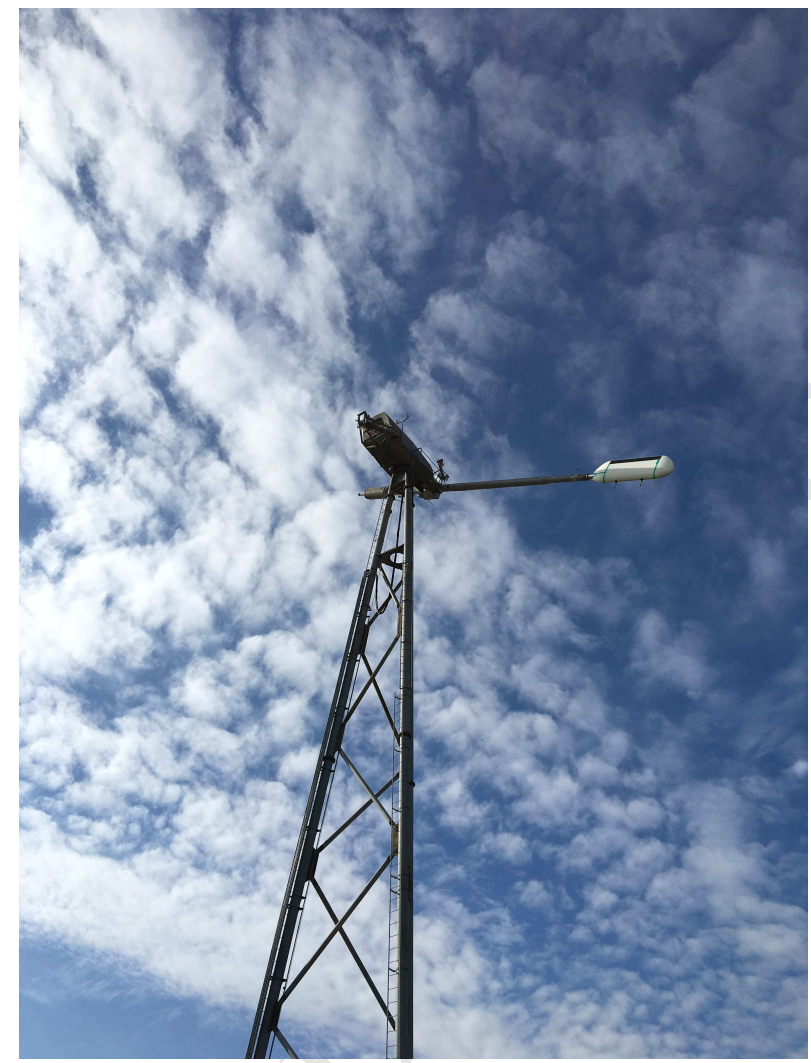

Figure 7: The blade section and the boom installed on the outdoor rotating rig.

phing flap at a range of angles of attack and Reynolds numbers representative of the scenarios in which the morphing flap could eventually operate on a MW-scale turbine. The angle of attack range is approximately $\pm 15^{\circ}$ under a normal production scenario. The angle of attack is defined using wind speed, rotor speed, and boom pitch. The Reynolds number is determined by wind speed and rotor speed and should be at least 1 million, and preferably 3 to 10 million. Due to vibration restrictions, the rig can only operate up to around $20 \mathrm{rpm}$, while the boom pitch is limited to $\pm 15^{\circ}$ about zero. Although the flap is capable of a maximum trailing edge deflection angle of $\pm 10^{\circ} \mathrm{deg}$, it has 
been limited to $\pm 5^{\circ}$ in all tests in order to limit any risk of placing extreme stress on the actuator. In all cases the rotor was placed at the mean wind direction.

The test matrix (see Table.1) was defined with the target to test the average aerodynamic performance of the morphing wing, its transient response, and its load control capability. Fig.8 depicts the control block diagrams used in the test.The following cases were tested in this campaign:

- Flap steps: steps of the flap angle to its maximum trailing edge deflection angle around the neutral position for average aerodynamic polars in atmospheric conditions and flap effectiveness;

- Periodic feed-forward flap control: azimuth-based flap angle variation to counteract periodic loading due to yaw misalignment;

- Inflow feed-forward flap control: proportional flap command based on filtered Pitot tube inflow angle.

In the flap step cases, 5 min tests were conducted with the flap angle fixed at zero, as well as with step changes in flap angle every 10 seconds for a range of pitch settings. These tests were sufficient to measure both the transient and steady state response of the aerodynamics to the changing morphing flap angles. For the case of square flap input signals, the derived aerodynamic data was averaged over smaller periods during the flap activation cycle. In all cases a square input of $0.025 \mathrm{~Hz}$ is used, so the flap activation cycle is divided into 4 sections of $10 \mathrm{~s}$ each. The positive flap region is defined as the 1st section, the neutral flap region as the 2nd section, and the negative flap region is defined as the 3rd section, as shown in Fig. 9, where the 
Table 1: Test cases in the rotating rig experiments.

\begin{tabular}{cccccc}
\hline case & rotor speed $(\mathrm{rpm})$ & pitch angle $\left(^{\circ}\right)$ & flap & runs & duration $(\mathrm{min})$ \\
\hline 1 & 20 & 0 & no & 2 & 5 \\
2 & 20 & 0 & steps & 2 & 5 \\
3 & 20 & 5 & no & 2 & 5 \\
4 & 20 & 5 & steps & 2 & 5 \\
5 & 20 & 10 & no & 2 & 5 \\
6 & 20 & 10 & steps & 2 & 5 \\
7 & 20 & 15 & no & 2 & 5 \\
8 & 20 & 15 & steps & 2 & 5 \\
9 & 20 & -15 & no & 2 & 5 \\
10 & 20 & -15 & steps & 2 & 5 \\
11 & 20 & -10 & no & 2 & 5 \\
12 & 20 & -10 & steps & 2 & 5 \\
13 & 20 & -5 & no & 2 & 5 \\
14 & 20 & -5 & steps & 2 & 5 \\
15 & 20 & -5 & azimuth control & 8 & 5 \\
16 & 20 & -5 & inflow control & 2 & 5 \\
& & \multicolumn{5}{c}{} \\
\hline
\end{tabular}

positive, neutral and negative flap regions are shown in red, black and green, respectively.

The second type of test concerns prescribed azimuth-based flap control, which comprises 5 min time series with the flap activated once per revolution towards its maximum positive or negative angles in order to counteract $1 \mathrm{P}$ periodic loading fluctuations. The flap signal comprises a $0.33 \mathrm{~Hz}$ harmonic signal $(1 / \mathrm{rev})$ with a tuned phase, which comprises an approximate halfsinusoidal signal from zero flap angle to either maximum positive or negative flap deflection (see Fig.9). All cases were conducted at a pitch setpoint of $-5^{\circ}$, which corresponds to an average angle of attack close to the design point. The flap was scheduled to be active for two revolutions, followed by two 

measured.

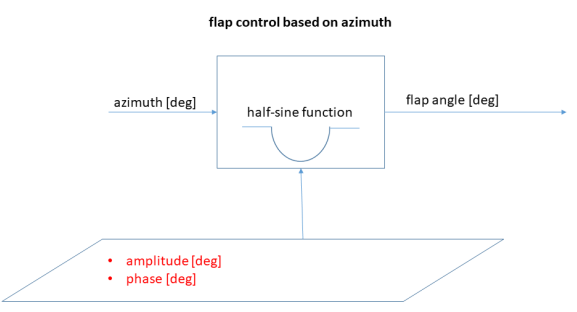

(a) Azimuth-based flap control block.

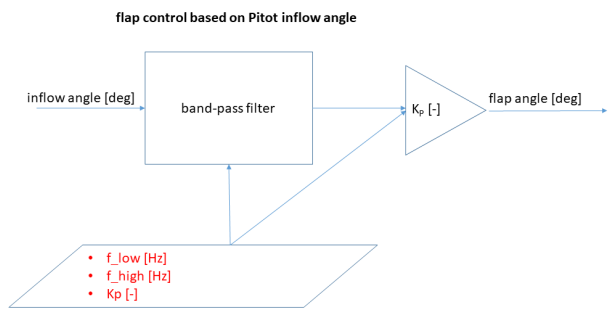

(b) Inflow angle-based flap control block.

Figure 8: The morphing flap control block diagram.

revolutions of no flap activation. In order to test this periodic controller, cases where the rotor was placed at an average of $30^{\circ}$ yaw misalignment were

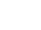
prises 5 min with the flap activated with a proportional gain on the band-pass filtered inflow angle from the outboard Pitot tube. The inflow angle signal was filtered between $0.04 \mathrm{~Hz}-1 \mathrm{~Hz}$, in order to remove the static gain and react to frequencies up to $3 \mathrm{P}$. The proportional gain was tuned in a fashion to take advantage of the whole morphing flap angle range for the maximum variation of the inflow. 


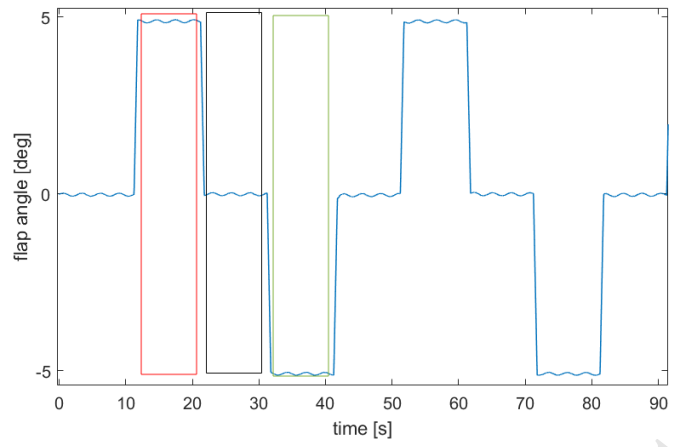

(a) Flap step signal indicating time periods of flap states for data binning (Red: positive flap position, black: neutral flap position, green: negative flap position).

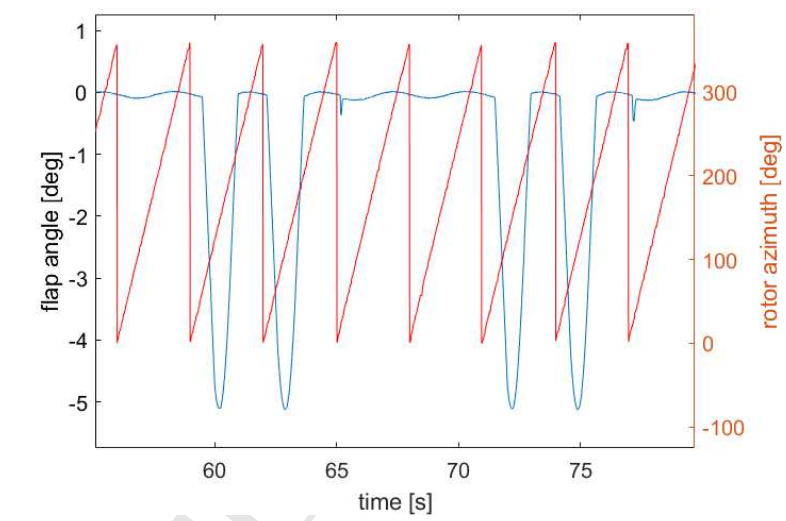

(b) Flap signal as a function of the rotor azimuth (activation at a phasedelayed blade top position in this case).

Figure 9: Morphing flaps control signal.

\subsection{Test results}

The integrated aerodynamic forces at the wing section were calculated from the pressure tap measurements on the aerofoil, also utilizing the Pitot tube pressure measurements. In one part of post-processing, the local flow angle and local flow velocity were derived from the Pitot tube pressure differences. In the remaining part of post-processing, the chordwise pressure tap data were utilized and corrected in order to calculate the integrated aerody- 


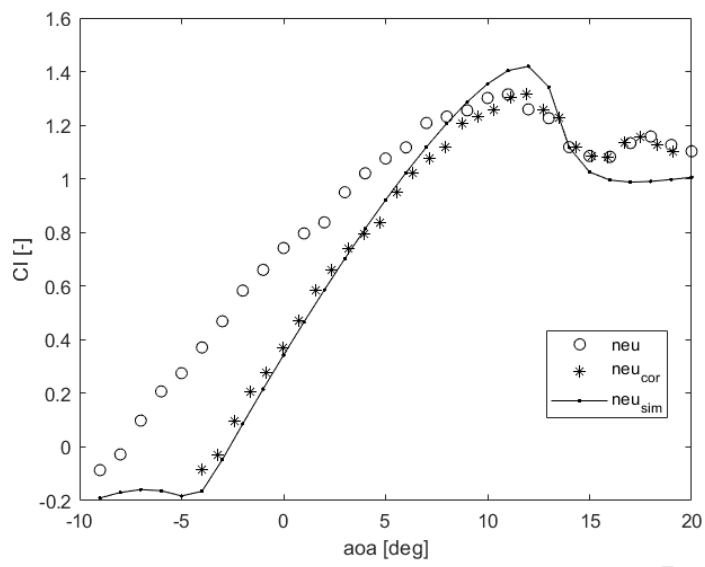

Figure 10: Binned measured $C_{l}$ data for: samples without flap activation (neu), data corrected for 3D effects and Pitot tube pressure offset $\left(\right.$ neu $\left._{\text {cor }}\right)$ and 2D CFD data $\left(\right.$ neu $\left._{\text {sim }}\right)$.

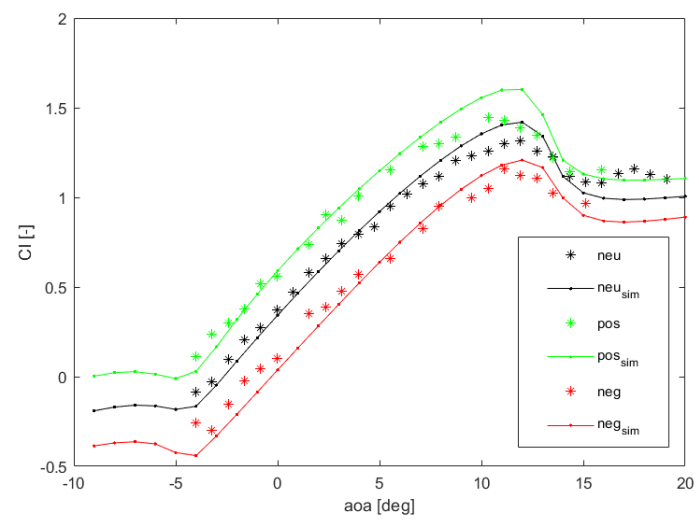

Figure 11: Binned measured $C_{l}$ data for: samples without flap activation $(n e u), 5^{\circ}$ morphing flap angle (pos), $-5^{\circ}$ morphing flap angle (neg) compared with 2D CFD data $\left(\right.$ neu $_{\text {sim }}$, pos sim $_{\text {sim }}$ and $\left.n e g_{\text {sim }}\right)$ as a function of angles of attack.

namic forces and coefficients. Computational fluid dynamic (CFD) methods were used in the data post-processing phase for verification.

For the flap step cases, the pressure data were post-processed and $C_{L}$ values sorted based on the angle of attack and flap angle average values. It is seen that the uncorrected binned measured polars have an angle of at- 


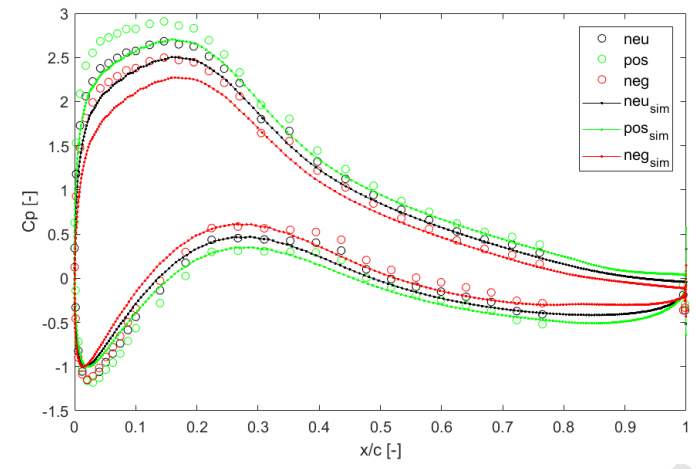

Figure 12: Binned measured $C_{p}$ data at angle of attack of $8^{\circ}$ for: samples without flap activation (neu), $5^{\circ}$ morphing flap angle (pos), $-5^{\circ}$ morphing flap angle (neg) compared with 2D CFD data $\left(\right.$ neu $_{\text {sim }}$, pos $_{\text {sim }}$ and negsim $)$.

tack offset and reduced slope compared to EllipSys 2D CFD fully turbulent RANS[27] (Fig.10). This difference arises due to 3D induction effects, upwash of the Pitot tube measurement point and an identified pressure drop in the measurement system. Corrections are utilized in order to establish an accurate translation of aerodynamic measurements on the rotating rig to $2 \mathrm{D}$ aerodynamic polars. The pressure drop discrepancy was corrected by comparing the pressure distributions to the CFD data, the Pitot tube upwash effect was derived based on simple 2D vorticity upwash, and the 3D induction effects were derived from Hawc2 simulations using the near-wake model[10]. The corrected data are shown to compare well with 2D CFD, especially in the linear region (see Fig.10). The binned corrected data for all average flap positions are then shown and compared to EllipSys 2D CFD fully turbulent RANS data in Fig. 11. It is shown that the overall aerodynamic impact of the flap is captured well, with an average estimated variations in the linear region of $\triangle C_{L}=+0.2$ and $\triangle C_{L}=-0.25$ for the $+5^{\circ}$ and $-5^{\circ}$ flap angle respectively. The CFD data provide an estimated average variation of 


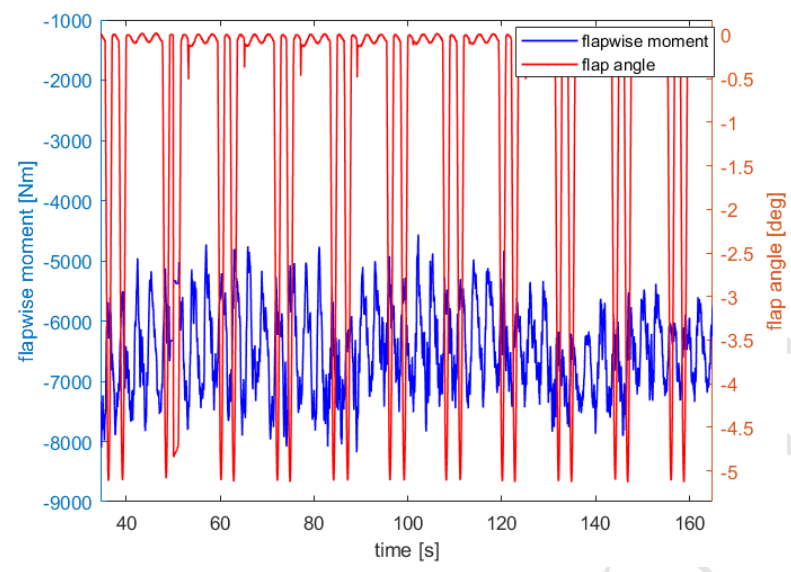

(a) Time series of flapwise moment and azimuth-based actuation of morphing flaps.

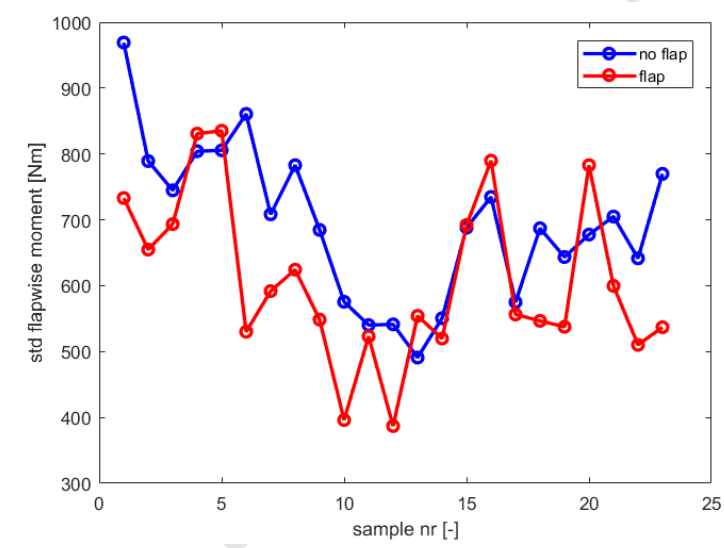

(b) Comparison of standard deviation of flpwise moment with azimuthbased morphing flap actuation.

Figure 13: Effects of azimuth-based morphing flap actuation on the flapwise moment responses.

$\triangle C_{L}=+0.25$ and $\triangle C_{L}=-0.3$

The pressure coefficient data $\left(C_{p}\right)$ are also binned around the design angle of attack of $8^{\circ}$ for the baseline and morphing angle range samples. The binned data are shown and compared to EllipSys 2D CFD data in Fig.12. It is shown that the overall $C_{p}$ curve shape is captured well, along with the effect of the 


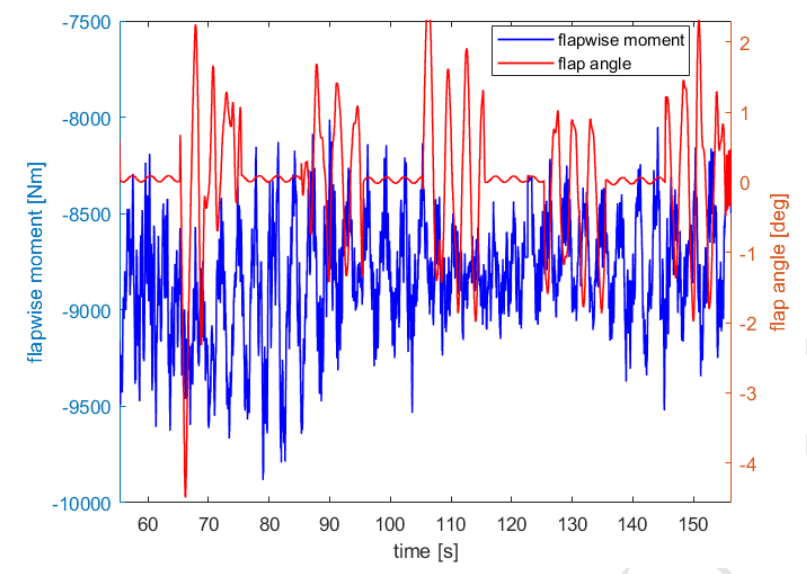

(a) Time series of flapwise moment and inflow-based actuation of morphing flaps.

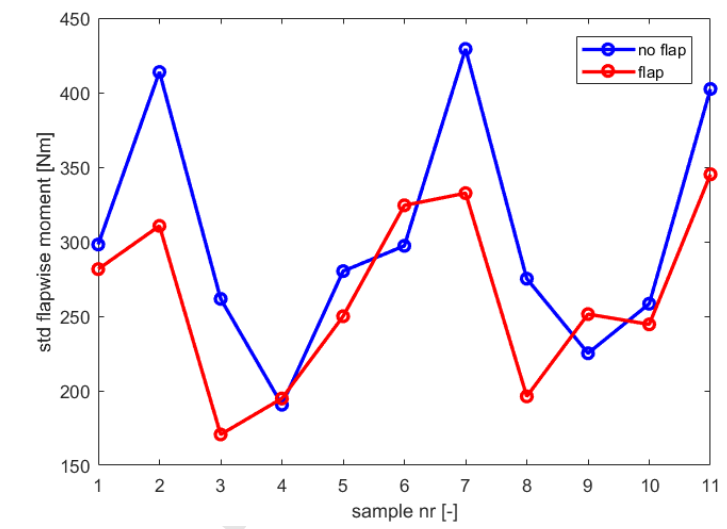

(b) Comparison of standard deviation of flpwise moment with inflowbased morphing flap actuation.

Figure 14: Effects of inflow-based morphing flap actuation on the flapwise moment responses.

morphing flap deflections.

The prescribed azimuth-based flap control comprises 5 min time series with the flap activated once per revolution towards its maximum positive or negative morphing angles in order to counteract $1 \mathrm{P}$ periodic loading fluctuations. The flap frequency is a $0.33 \mathrm{~Hz}$ harmonic signal $(1 / \mathrm{rev})$ with a tuned 
phase, which has an approximate half-sinusoidal signal from zero flap angle to either maximum positive or negative morphing flap angles (see Fig.13). All tests were conducted at a pitch setpoint of $-5^{\circ}$, which corresponds to an average angle of attack close to the design point. The flap was scheduled to be active for two revolutions, followed by two revolution of no flap activation. In order to test this periodic controller, cases where the rotor is placed at an average $30^{\circ}$ yaw misalignment were measured. The data from the flapwise strain sensor was collected and post-processed and sorted for every sample consisting of two revolutions without control and two revolutions with the morphing flap controller active. The statistics of every consecutive samples are then compared. The time series of the flapwise moment at the connection of the wing to the boom is shown in Fig.13, together with the morphing flap angle which is activated for two revolutions followed by two revolutions without activation. The morphing flap angle is driven to the maximum negative angle of $-5^{\circ}$ when the blade is at its top position, targeting the alleviation of peak loading. The comparison of the standard deviation of the flapwise moment for every consecutive sample of no activation and azimuth-based flap activation is shown in Fig.13. Although, as expected, the prescribed azimuthbased flap activation is not robust, it results in an average reduction of the standard deviation of the flapwise moment of $12 \%$.

For the inflow flap control cases, the data from the flapwise strain sensor were post-processed and sorted for every sample consisting of $10 \mathrm{~s}$ without control and $10 \mathrm{~s}$ with the feed-forward inflow-based flap controller active. The statistics of every consecutive sample are then compared. The time series of the flapwise moment at the connection of the wing to the boom 
are shown in Fig.14, together with the flap angle which is activated for 10 $\mathrm{s}$ followed by $10 \mathrm{~s}$ without activation. The morphing flap angle in this case reacts to fluctuations of the inflow angle within the band-pass filtered range of frequencies up to 3P. The comparison of the standard deviation of the flapwise moment for every consecutive sample of no activation and azimuthbased flap activation is shown in Fig.14. The morphing flap controller results in an average reduction of the standard deviation of the flapwise moment of $11 \%$.

As the test results show, the morphing device proposed herein, in comparison with conventional blades, improves wind turbine blade performance in terms of lif-to-drag ratios, flow fluctuation attenuation and also blade load optimization. The overall performance enhancement effects of the morphing flap result from the pressure changes on the blade surface along the aerofoil chord and the blade span which was caused by the geometric variations of the blade profiles. A previous study [13] has shown that cambered morphing trailing edges can significantly influence the pressure envelope of the aerofoil including the leading edge, the flow wake developed rearward of the aerofoil and also the boundary layer profiles.

\section{Conclusions}

A morphing trailing edge device that has been designed, manufactured and benchmarked as a novel flow control method has been successfully tested on an outdoor rotating test rig. Results confirm the effectiveness of the morphing flaps on lift control and dynamic load alleviation for the turbine blade. 
Morphing flaps consisting of CFRP laminate and 3D-printed honeycomb core were tested mechanically considering actuation requirements, activation frequency, i.e. the response speed of the flap system and also fatigue performance. Based on the geometry and material properties specified in this design case, a pushing and/or pulling force of up to $250 \mathrm{~N}$ was needed for the flap's full deployment, about $5 \%$ of the blade aerofoil chord (50 mm) towards both the pressure and suction sides. However, due to limits on power of the linear servo-motor, only half of the maximum designed trailing edge deformation capability was tested on the outdoor testing rig yet still provides significantly promising results.

The outdoor testing campaign using a rotating test rig adds rigour and robustness to the morphing flaps in this paper for future development purposes. The morphing flap fitted on the test bed section has provided enhanced aerodynamic pressure and hence lift control capability to the blade. Furthermore, when combined with inflow sensors, they can significantly alleviate adverse effects of the dynamic loads on the blade structure. The test campaign successfully demonstrated the potential of the new flow control devices, the morphing flap system and showed its viability for wind turbine blades. However, challenges remain before commercialisation and to address them, future work could include:

- In the current test campaign, all eight morphing flaps fitted on the blade section are programmed to provide uniform trailing edge deflection along the span while in future, a more complex test case using a separate actuation system for each morphing flap so as to provide spanwise geometry changes together with chordwise cambering could 
be further investigated;

- As a device proposed to help improve aerodynamic performance of wind turbine blades, a future systematic study on the methodology of reducing energy cost using morphing flaps could present a better outlook of morphing concepts and their potential commercial benefits;

- To better understand the flow physics and performance improvement mechanisms, flow field measurements of the morphing flaps installed on the rotating rig should be carried out;

- Currently, a united actuation system using a linear motion servo motor was used and in future, an improved system with potentially reduced weight and cost can be investigated to better facilitate the holistic control method using morphing flaps.

\section{Acknowledgement}

The research leading to these results has received funding from the European Communitys Seventh Framework Programme under grant agreement No. 308974 (INNWIND.EU). PMW would like to thank SFI for funding Varicomp under its research professor scheme (Grant no.:15/RP/2773) and also to the Royal Society under its Wolfson Merit Award.

[1] Kaldellis J.K, Zafirakis D. The wind energy (r)evolution: A short review of a long history. Renewable Energy 2011; 36:1887-1901. DOI: 10.1016/j.renene.2011.01.002. 
[2] Barlas T.K., van Kuik G.A.M. Review of state of the art in smart rotor control research for wind turbines. Progress in Aerospace Sciences 2010; 46(27). doi:10.1016/j.paerosci.2009.08.002.

[3] Lachenal, X., Daynes, S., Weaver, P. 2013. Review of morphing concepts and materials for wind turbine blade applications. Wind Energy, Vol. 16, pp: 283-307. DOI: 10.1002/we.531.

[4] Aagaard Madsen, H., Barlas, T., Løgstrup Andersen, T. A morphing trailing edge flap system for wind turbine blades. Proceedings of the Tth ECCOMAS thematic conference on smart structures and materials. 3-6 June 2015, Azores, Portugal.

[5] Barlas, T., Pettas, V., Gertz, D., Madsen, H.A. Extreme load alleviation using industrial implementation of active trailing edge flaps in a full design basis. Journal of Full Physics: Conference Series 753. 2016, 042001. Doi:10.1088/1742-6596/753/4/042001.

[6] Aagaard Madsen, H., Andersen, P. B., Lgstrup Andersen, T., Bak, C., Buhl, T., Li, N. The potentials of the controllable rubber trailing edge flap (CRTEF). Ewec 2010 Proceedings Online. 2010. Published: 2010.

[7] Aagaard Madsen, H., Lgstrup Andersen, T., Bergami, L., Jrgensen, J. E., Candela Garolera, A., Holbll, J., Christensen, M. B. Towards an industrial manufactured morphing trailing edge flap system for wind turbines. Proceedings of Ewea 2014. Published: 2014.

[8] Barlas, A, Aagaard Madsen , H, Enevoldsen, K, Klemmensen, K 2014, 
Flap testing on the rotating test rig in the INDUFLAP project. DTU Wind Energy. DTU Wind Energy E, no. 0064(EN)

[9] Caboni M., Boorsma K. and Kanev S. Development of thick airfoils for outboard sections and investigations into their applications for large rotors. Chapter 2 in Innwind report D2.14 New aero-structure rotor concepts and evaluation for $20 \mathrm{MW}$ turbines, edited by H Aa Madsen, 2017.

[10] Pirrung, GR, Aagaard Madsen , H, Kim, T., Heinz, JC. A coupled near and far wake model for wind turbine aerodynamics. Wind Energy, 2016. Vol: 19(11), pp. 20532069. DOI: 10.1002/we.1969

[11] Zhang M, Yu W., Xu J. Aerodynamic physics of smart load control for wind turbine due to extreme wind shear. Renewable Energy 2014; 70:204-210. DOI: 10.1016/j.renene.2013.12.046.

[12] Zhang M., Tan B., Xu J. Parameter study of sizing and placement of deformable trailing edge flap on blade fatigue load reduction. Renewable Energy 2015; 77:217-226. DOI: 10.1016/j.renene.2014.12.022.

[13] Kamliya Jawahar H, Ai Q., Azarpeyvand M. Experimental and numerical investigation of aerodynamic performance for airfoils with morphed trailing edges. Renewable Energy 2018; 127:355-367. DOI: 10.1016/j.renene.2018.04.066.

[14] Zhang M., Tan B., Xu J. Smart fatigue load control on the large-scale wind turbine blades using different sensing signals. Renewable Energy 2016; 87:111-119. DOI: 10.1016/j.renene.2015.10.011. 
[15] Daynes S, Weaver P. A morphing trailing edge device for a wind turbine. Journal of Intelligent Material Systems and Structures 2012; 23: 691701. DOI:10.1177/1045389X12438622.

[16] Daynes S, Weaver P. Design and testing of a deformable wind turbine blade control surface. Smart Materials and Structures 2012; 21:105019105029. DOI:10.1088/0964-1726/21/10/105019.

[17] Ai, Q., Azarpeyvand, M., Lachenal, X., Weaver, P. 2015. Aerodynamic and aeroacoustic performance of airfoils using morphing structures, Wind Energy, Vol. 19(7), pp: 1325-1339. DOI: 10.1002/we.1900.

[18] Bergami L, Riziotis V.A, Gaunaa M. Aerodynamic response of an airfoil section undergoing pitch motion and trailing edge flap deflection: a comparison of simulation methods. Wind Energy 2014; Early Version, DOI: $10.1002 /$ we. 1759

[19] Wolf A, Lutz T, Wurz W, Kramer E, Stalnov O, Seifert A. Trailing edge noise reduction of wind turbine blades by active flow control. Wind Energy 2014.DOI: 10.1002/we.1737.

[20] Ai, Q., Weaver, P., Azarpeyvand, M. 2017. Design and mechanical testing of a variable stiffness morphing trailing edge flap, Journal of Intelligent Material Systems and Structures, First Published Online July 28 2017. DOI: $10.1177 / 1045389 X 17721028$.

[21] Olympio, KR., Gandhi, F. 2009. Flexible skins for morphing aircraft using cellular honeycomb cores. Journal of Intelligent Material Systems and Structures,Vol. 21, pp:1719-1735. DOI:10.1177/1045389X09350331. 
[22] Olympio, KR., Gandhi, F. 2010. Zero Poisson's ratio cellular honeycombs for flex skins undergoing one-dimensional morphing. Journal of Intelligent Material Systems and Structures, Vol. 21, pp:1737-1753. DOI: $10.1177 / 1045389 X 09355664$.

[23] Bartley-Cho, JD., Wang, DP., Martin, CA., Kudva, JN., West, MN. 2004. Development of high-rate, adaptive trailing edge control surface to the smart wing phase 2 wind tunnel model. Journal of Intelligent Material Systems and Structures, Vol. 15, pp: 279-291. DOI:10.1177/1045389X04042798.

[24] Bubert, EA., Woods, B KS., Lee, K., Kothera, CS., Wereley, NM. 2010. Design and fabrication of a passive 1D morphing aircraft skin. Journal of Intelligent Material Systems and Structures, Vol. 21, pp:1699-1717. DOI:10.1177/1045389X10378777.

[25] Campanile LF.2007. Adaptive Structures: Engineering Applications (Wagg D, Bond IP, Weaver PM, Friswell MI, eds). Wiley:Chichester, Chapter 4: Lightweight Shape-adaptable Airfoils: A New Challenge for an Old Dream.

[26] Drela M, Youngren H. Xfoil 6.8 User Primer; Massachusetts Institute of Technology, Cambridge, Massachusetts, 2001.

[27] Sørensen N., General purpose flow solver applied to flow over Hills. Ris $\varnothing-$ R-827-(EN), Risø National Laboratory, Roskilde, Denmark, June 1995. 
Author's Novelty:

1) The application of morphing structures for simultaneous improvement of the aerodynamic performance of wind turbine blades

2) Design, modelling and prototyping of a morphing flap concept using $3 \mathrm{D}$ printed honeycomb core and carbon fibre laminate

3) Outdoor testing of morphing flaps mounted on a blade section using a rotating testing rig in field for realistic effects

4) Results confirmed the improved aerodynamic enhancement and also the dynamic load alleviation effects achieved using the proposed blade control methods with morphing flaps 